Pesq. Vet. Bras. 35(5):403-408, maio 2015 DOI: $10.1590 / \mathrm{S} 0100-736 \mathrm{X} 2015000500003$

\title{
Molecular survey of porcine teschovirus, porcine sapelovirus, and enterovirus $G$ in captive wild boars (Sus scrofa scrofa) of Paraná state, Brazil ${ }^{1}$
}

\author{
Daiane G. Donin ${ }^{3}$, Raquel de A. Leme ${ }^{2}$, Alice F. Alfieri² ${ }^{2}$, Geraldo C. Alberton ${ }^{3}$ \\ and Amauri A. Alfieri ${ }^{2 *}$
}

\begin{abstract}
Donin D.G., Leme R.A., Alfieri A.F., Alberton G.C. \& Alfieri A.A. 2015. Molecular survey of porcine teschovirus, porcine sapelovirus, and enterovirus $G$ in captive wild boars (Sus scrofa scrofa) of Paraná state, Brazil. Pesquisa Veterinária Brasileira 35(5):403-408. Laboratório de Virologia Animal, Departamento de Medicina Veterinária Preventiva, Universidade Estadual de Londrina, Rodovia Celso Garcia Cid, Campus Universitário, Cx. Postal 10011, Londrina, PR 86057-970, Brazil. E-mail: alfieri@uel.br

Porcine teschovirus (PTV), porcine sapelovirus (PSV), and enterovirus G (EV-G) are infectious agents specific to pig host species that are endemically spread worldwide. This study aimed to investigate the natural infection by these porcine enteric picornaviruses in wild boars (Sus scrofa scrofa) of Paraná state, Brazil, and to evaluate peccaries (Pecari tajacu and Tayassu pecari) as alternative host species for these viruses. Fecal samples $(n=36)$ from asymptomatic wild boars $(n=22)$ with ages ranging from 2 to 7 months old (young, $n=14)$ and 2 to 4 years old (adult, $n=8$ ) and from peccaries ( 6 to 8 months old, $n=14$ ) were collected from a farm and a zoo, respectively, both located in Paraná state. Reverse transcription-polymerase chain reaction (RT-PCR) and nested-PCR (n-PCR) assays targeting the 5'non-translated region of the virus genome were used for screening the viruses. Porcine enteric picornaviruses were detected in 12 out of the 22 wild boar fecal samples. According to each of the viruses, EV-G was most frequently $(11 / 22,50 \%)$ detected, followed by PTV $(10 / 22,45.5 \%)$ and PSV $(4 / 22,18.2 \%)$. Regarding the age groups, young wild boars were more frequently $(9 / 14,64.3 \%)$ infected with PTV, PSV, and EV-G than adult animals (3/8, 37.4\%). One n-PCR amplified product for each of the viruses was submitted to sequencing analysis and the nucleotide sequences were compared with the related viruses, which showed similarities varying from $97.7 \%$ to $100 \%$ for PTV, $92.4 \%$ to $96.2 \%$ for PSV, and $87.1 \%$ to $100 \%$ for EV-G. Peccaries tested negative for the viruses and in this study they did not represent infection reservoirs. This study is the first to report the molecular detection of PTV, PSV, and EV-G from captive wild boars in a South American country and the first to screen peccaries as alternative host species for porcine enteric picornavirus.
\end{abstract}

INDEX TERMS: Porcine teschovírus, PTV, porcine sapelovírus, PSV, enterovírus G, EV-G, wild boars, Pecari tajacu, Sus scrofa scrofa, Tayassu pecari.

RESUMO.- [Estudo molecular de teschovírus suíno, sapelovírus suíno e enterovírus G em javalis (Sus scrofa scrofa) de cativeiro no Paraná.] Teschovírus suíno (PTV),

\footnotetext{
${ }^{1}$ Received on January 15, 2015.

Accepted for publication on March 5, 2015.

${ }^{2}$ Laboratório de Virologia Animal, Departamento de Medicina Veterinária Preventiva, Universidade Estadual de Londrina (UEL), Rodovia Celso Garcia Cid, Campus Universitário, Cx. Postal 10011, Londrina, PR 86057970, Brazil.*Corresponding author: alfieri@uel.br

${ }^{3}$ Departamento de Medicina Veterinária, Universidade Federal do Paraná (UFPR), Rua Pioneiro 2153, Palotina, PR 85950-000, Brazil.
}

sapelovírus suíno (PSV) e enterovírus G (EV-G) são agentes infecciosos específicos da espécie suína que estão endemicamente disseminados em todo o mundo. 0 objetivo deste estudo foi investigar a infecção natural por estes picornavírus entéricos suínos em javalis (Sus scrofa scrofa) do estado do Paraná, Brasil e avaliar pecaris (Pecari tajacu e Tayassu pecari) como hospedeiros alternativos para estes vírus. Amostras fecais $(n=36)$ de javalis assintomáticos $(n=22)$ com idades de 2 a 7 meses (jovens, $n=14$ ) e 2 a 4 anos (adultos, $n=8$ ) e de pecaris ( 6 a 8 meses de idade, $n=14$ ) foram coletadas em um cativeiro e zoológico, res- 
pectivamente, ambos localizados no estado do Paraná. A transcrição reversa seguida por reações da polimerase em cadeia (RT-PCR) e nested-PCR com alvo na região 5'-não traduzida do genoma viral foram utilizadas para a identificação dos vírus. Picornavírus entéricos suínos foram detectados em 12 das 22 amostras fecais de javalis. De acordo com cada um dos vírus, EV-G foi mais frequentemente $(11 / 22,50 \%)$ detectado, seguido pelo PTV $(10 / 22$; $45,5 \%)$ e PSV $(4 / 22 ; 18,2 \%)$. Considerando os grupos de idade, javalis jovens foram mais frequentemente $(9 / 14$; $64,3 \%$ ) infectados com PTV, PSV e EV-G do que os javalis adultos $(3 / 8 ; 37,4 \%)$. Um produto amplificado na nested-PCR para cada um dos vírus foi submetido à análise de sequenciamento e as sequências de nucleotídeos foram comparadas com vírus relacionados, o que mostrou que as similaridades variaram entre $97,7 \%$ a $100 \%$ para o PTV, $92,4 \%$ a $96,2 \%$ para o PSV e $87,1 \%$ a $100 \%$ para o EV-G. Os pecaris foram negativos para as viroses investigadas e neste estudo não se apresentaram como hospedeiros alternativos para as infecções. Este estudo é o primeiro a relatar a detecção molecular de PTV, PSV e EV-G em javalis de cativeiro de um país da América Latina e o primeiro a avaliar pecaris como espécie hospedeira alternativa para picornavírus entéricos suínos.

TERMOS DE INDEXAÇÃO: Teschovírus suíno, PTV, sapelovírus suíno, PSV, enterovírus G, EV-G, javalis, Pecari tajacu, Sus scrofa scrofa, Tayassu pecari.

\section{INTRODUCTION}

Porcine teschovirus (PTV), porcine sapelovirus (PSV), and enterovirus $G$ (EV-G), also known as porcine enteric picornaviruses, are common pathogens that only cause infections in pigs. These viruses belong to the Picornaviridae family and are small, non-enveloped, and have a single-stranded positive-sense RNA (ssRNA) genome (ICTV 2013).

Porcine enteric picornaviruses have previously been classified in the Enterovirus genus, which was composed of at least 13 species, named PEV1 through PEV13. Studies on the biological and molecular features of porcine enteroviruses have led to their reclassification into 3 distinct genera. The species PEV1 to 7 and PEV11 to PEV13 have been reclassified into the genus Teschovirus, which is composed of different serotypes of a single species named porcine teschovirus (Kaku et al. 2001, Zell et al. 2001). The species PEV8 was named as porcine enterovirus $A$ and was later renamed porcine sapelovirus, representing the unique porcine host species of the new genus Sapelovirus (Krumbholz et al. 2002). The species PEV9 and PEV10 have been classified into the genus Enterovirus, species porcine enterovirus $B$ (PEV-B), which was recently renamed as enterovirus $G$ (Krumbholz et al. 2003, ICTV 2013).

The majorities of the PTV, PSV, and EV-G serotypes are non-pathogenic and circulate worldwide in asymptomatic domestic pigs (Cano-Gómez et al. 2011, Prodělalová 2012). However, depending on the virus serotype and infection conditions, these picornaviruses may be considered important etiological agents of enteric, respiratory, reproductive, or neurological disorders (Bangari et al. 2010, Ventura et al. 2013). Clinical manifestations may include diarrhea, pneumonia, febrile illness, vesicular diseases, reproductive failure (SMEDI syndrome), myocarditis, and polioencephalomyelitis (Krumbholz et al. 2003).

Studies performed in different geographical regions throughout the world revealed that PTV, PSV, and EV-G are ubiquitous and have been reported in Asia (Kaku et al. 2007, Lan et al. 2011, Lin et al. 2012, Moon et al. 2012, Zhang et al. 2012), Europe (Zell et al. 2000, La Rosa et al. 2006, Buitrago et al. 2010, Sozzi et al. 2010, Boros et al. 2011, Prodělalová 2012), and the Americas (Bangari et al. 2010, Salles et al. 2011, Shan et al. 2011, Deng et al. 2012, Ventura et al. 2013, Donin et al. 2014).

The role of wild boars (Sus scrofa scrofa, Suidae family) as a reservoir of infectious disease for other domestic animals and human populations has been discussed for years (Ruiz-Fons et al. 2008, Meng et al. 2009). Wild boars are susceptible to infections by viruses that also affect domestic pigs (Sus scrofa domesticus), such as porcine group A rotavirus (PoRVA), porcine circovirus type 2 (PCV2), hepatitis E virus (HEV), Aujeszky disease virus (ADV), porcine parvovirus (PPV), porcine reproductive and respiratory syndrome virus (PRRSV), classical swine fever virus (CSF), torque teno sus virus (TTSuV), influenza A virus, and others (Ruiz-Fons et al. 2008, Meng et al. 2009, Okadera et al. 2013, Biondo et al. 2014). These animals are also susceptible to infections by PTV, PSV, and EV-G, which were described in asymptomatic wild boars in Hungary (Boros et al. 2012a, Boros et al. 2012b), Spain (Cano-Gómez et al. 2013), and the Czech Republic (Prodělalová 2012).

The uncontrolled growth of the wild boar populations has been observed worldwide over the last decades. Wild boars can easily adapt to different food and environmental conditions, which, together with other enabling factors, favor the wide geographical distribution of this animal species (Bieber \& Ruf 2005). In Brazil, there is a similar scenario, in which wild boars are present in many states, in both free and captive situations (Deberdt \& Scherer 2007).

Pecari tajacu and Tayassu pecari, also known as "cateto" and "queixada", respectively, are wild animals earlier believed to be related to the genus Sus and reclassified as genera Pecari and Tayassu into the Tayassuidae family (Taber et al. 2011). Sus scrofa, Pecari tajacu, and Tayassu pecari belong to the same order (Artiodactyla) and largely distributed in distinct geographical regions of Latin America.

The health status of South American wild boar populations in regards to porcine picornavirus natural infection is not known. Due to the increase in wild boar populations in Brazil, the role these animals may play as reservoirs for viral infectious diseases, and the recently reported endemic circulation of porcine enteric picornaviruses in Brazilian pig herds (Donin et al. 2014), this study aimed to investigate the occurrence of natural infection by PTV, PSV, and EV-G from the wild boars of Paraná state, Brazil. Additionally, these porcine enteric picornaviruses were evaluated in Pecari tajacu and Tayassu pecari, both generally called peccaries, in order to investigate a possible alternative host species for these viruses. 


\section{MATERIALS AND METHODS}

This study is in agreement with the ethical principles complied by the Brazilian College of Animal Experimentation (COBEA) and was approved by the Animals Use Ethics Committee (CEUA/protocol number 22/2013) of the Universidade Federal do Paraná Palotina sector.

Thirty-six fecal samples from wild animals of Paraná state, southern Brazil, were evaluated. Young ( 2 to 7 months old, $n=14$ ) and adult ( 2 to 4 years old, $n=8$ ) asymptomatic wild boars living on a farm $\left(25^{\circ} 27^{\prime} 18.5^{\prime \prime} \mathrm{S}\right.$; $\left.54^{\circ} 25^{\prime} 41.8^{\prime \prime} \mathrm{W}\right)$ were sampled in June, 2013. The farm was licensed by the Brazilian Institute of Environment and Renewable Natural Resources - IBAMA (registration number 02017019336/97-06). Pecari tajacu $(n=5)$ and Tayassu pecari $(n=9)$ animal species with ages ranging 6 to 8 months old were sampled on a zoo located in the Natural Reserve Park of Cascavel city (24⒌'21"S, 53²7'18”W) in March, 2014. The animals were maintained in captivity, had no contact with domestic pigs, and were bred in a livestock-like management system, following the requirements commonly applied to commercial pig herds in Brazil. Aliquots of the collected fecal samples were properly labelled and sealed and stored at $-80^{\circ} \mathrm{C}$ until used for analysis.

Fecal suspensions were prepared at 10 to $20 \%(\mathrm{w} / \mathrm{v}$ ) in 0.01 $\mathrm{M}$ phosphate-buffered saline (PBS, $\mathrm{pH}$ 7.2) and centrifuged at $5,000 \times g$ for $3 \mathrm{~min}$. The supernatants were used for nucleic acid extraction.

RNA was extracted using a combination of phenol/chloroform/isoamyl alcohol (25:24:1) and silica/guanidinium isothiocyanate nucleic acid extraction methods (Boom et al. 1990, Alfieri et al. 2006). The RNA was eluted in $50 \mu$ l of ultra-pure RNase-free diethylpyrocarbonate (DEPC)-treated sterile water and immediately submitted to a reverse transcription reaction (RT) assay. One porcine enteric picornavirus positive fecal sample (BRA/UEL3/13, GenBank accession numbers KF410644 and KF410645), and an aliquot of ultrapure autoclaved water were included as positive and negative controls, respectively, during the nucleic acid extraction and the following procedures.

Polymerase chain reaction (PCR) and nested-PCR (n-PCR) assays were performed using primers for each of the viruses, targeting the 5'-non-translated region (5'-NTR) of the porcine enteric picornavirus genomes (Krumbholz et al. 2003). The technique was performed as described previously (Krumbholz et al. 2003), with modifications (Donin et al. 2014). The expected fragment lengths of n-PCR amplified products were $158 \mathrm{bp}$ (PTV), $212 \mathrm{bp}$ (PSV), and 313 bp (EV-G).

One amplified product in the n-PCR assay for each of the viruses was randomly selected for sequencing and phylogenetic analysis. The n-PCR amplicons were purified by GFX ${ }^{\mathrm{TM}}$ PCR DNA and the Gel Band Purification Kit (GE Healthcare, Little Chalfont, UK), quantified with a Qubit ${ }^{\mathrm{TM}}$ Fluorometer (Invitrogen ${ }^{\mathrm{TM}}$ Life Techno- $^{-}$ logies, Eugene, OR, USA), and sequenced in both directions with forward and reverse primers in an ABI 3500 Genetic Analyser with the BigDye ${ }^{\mathrm{TM}}$ Terminator v3.1 Cycle Sequencing Kit (Applied Biosystems ${ }^{\circledR}$, Foster City, CA, USA). Sequence quality analyses and consensus nucleotide (nt) sequences were assembled using the Phred/Phrap/CAP3 software (http://asparagin.cenargen.embrapa.br/phph/). Similarity searches were performed with sequences deposited in GenBank using the Basic Local Alignment Search Tool - BLAST software (http://blast.ncbi.nlm.nih.gov/Blast. cgi). A phylogenetic tree, based on nucleotides, was obtained using MEGA version 6.05 (Tamura et al. 2013) by the maximum likelihood statistical method based on the kimura two-parameter model, which provided statistical support via bootstrapping with 1,000 replicates. A sequence identity matrix was performed using the BioEdit software version 7.1.11 (http://www.mbio.ncsu.edu/ bioedit/bioedit.html).

\section{RESULTS}

Porcine enteric picornaviruses were detected in 12 of the 22 wild boar fecal samples analyzed. Considering all of the samples, EV-G was detected most frequently $(50 \%, 11 / 22)$, followed by PTV $(45.5 \%, 10 / 22)$. PSV was the least $(18.2 \%$, $4 / 22$ ) common virus present in the fecal samples evaluated and was not detected in the adult wild boar group.

Double PTV and EV-G $(22.7 \%, 5 / 22)$ and triple PTV, PSV, and EV-G $(18.2 \%, 4 / 22)$ infections were more frequently detected, followed by EV-G $(9.1 \%, 2 / 22)$ as a single infection. Regarding the different ages, 2- to 7-month-old wild boars presented with a higher frequency $(64.3 \%, 9 / 14)$ of enteric picornaviruses than animals aged 2 to 4 years-old $(37.5 \%, 3 / 8)$. The results are summarized in Table 1 . Fecal samples from Pecari tajacu and Tayassu pecari tested negative for the 3 viruses.

Table 1. Single and mixed infections with porcine teschovírus (PTV), porcine sapelovírus (PSV), and enterovírus $G$ (EV-G) detected by n-PCR assays from fecal samples of wild boars (Sus scrofa scrofa) in Paraná state, Brazil

\begin{tabular}{lccc}
\hline Porcine enteric & \multicolumn{2}{c}{ Age group } & $\begin{array}{c}\text { Total } \\
(n=22)\end{array}$ \\
\cline { 2 - 3 } & $\begin{array}{c}\text { Young } \\
\text { picornaviruses }\end{array}$ & $\begin{array}{c}\text { Adult } \\
\text { (2 to } 7 \text { months old }) \\
n=14\end{array}$ & $\begin{array}{c}\text { (2 to years old }) \\
n=8\end{array}$ \\
\hline PTV & 01 & - & 01 \\
PSV & - & - & - \\
EV-G & - & 02 & 02 \\
PTV + PSV & - & - & - \\
PTV + EV-G & 04 & 01 & 05 \\
PSV + EV-G & - & - & - \\
PTV + PSV + EV-G & 04 & - & 04 \\
Total & 09 & 03 & 12
\end{tabular}

The sequencing of one amplicon per each virus confirmed the specificity of the amplified products. The fragment sizes of amplicons were $157 \mathrm{nt}$ for PTV (BRA/UEL-WB01/13, nt sequences $<200 \mathrm{bp}$; therefore not submitted to the GenBank and available at the Figure legend herein), $211 \mathrm{nt}$ for PSV (BRA/UEL-WB20/13, GenBank accession number KJ187770), and 313 for EV-G (BRA/UEL-WB40/13, GenBank accession number KJ187771).

Porcine enteric picornavirus nt sequences in this study and others available in GenBank presented similarities varying from 98.4 to $100 \%$ for PTV, $92.4 \%$ to $96.2 \%$ for PSV, and 87.1 to $99.2 \%$ for EV-G. The similarities of sequences herein with other nt sequences from PTV, PSV, and EV-G Brazilian field strains previously reported varied from $97.7 \%$ to $98.4 \%$ for PTV, $95.4 \%$ for PSV, and $99.2 \%$ to $100 \%$ for EV-G. The phylogenetic tree formed 3 clusters, with each of the porcine enteric picornavirus strains from wild boars of Brazil clustered together with their related viruses. The different serotypes of PTV, PSV, and EV-G evaluated in this study are presented in the phylogenetic tree, with the GenBank accession number of each of the virus sequence presented in parentheses (Fig.1). 


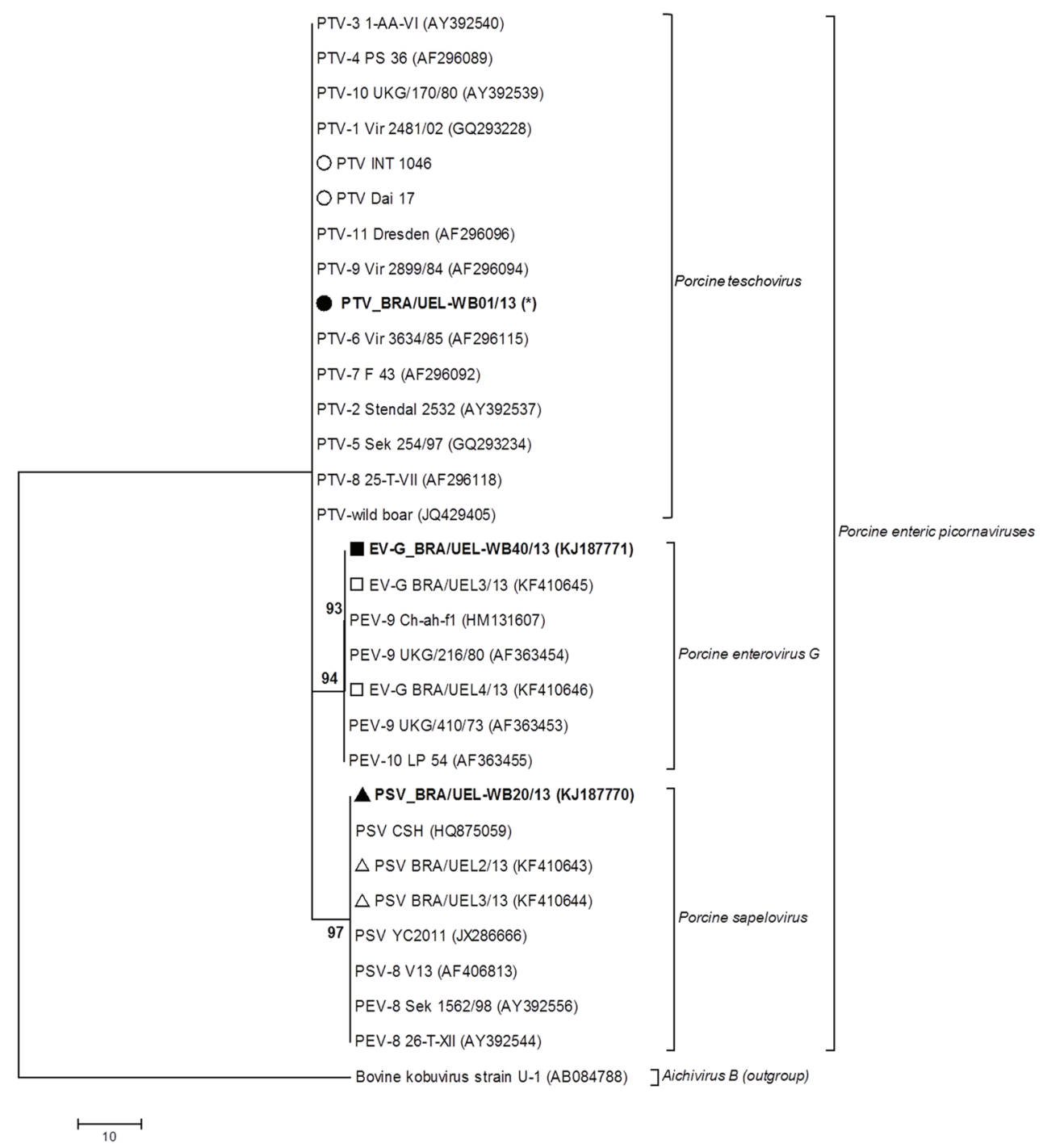

Fig.1. Maximum likelihood phylogenetic tree construction using the kimura two-parameter model based on the partial (130 nt) 5'-non-translated region of porcine enteric picornavirus strains available in GenBank, previously published sequences of Brazilian strains (indicated by O - PTV, $\Delta$ - PSV, and $\square-$ EV-G) and Brazilian PTV (• BRA/UEL-WB01/13), PSV ( $\Delta$ BRA/UEL-WB20/13), and EV-G ( BRA/UEL-WB40/13) wild boar strain sequences in this study. A bovine kobuvirus nt sequence was used as the outgroup. The GenBank accession numbers of the representative sequences and Brazilian strains presented herein are indicated in parentheses. Bootstrap values determined in 1,000 replications. (*) refer to PTV nt sequence < $200 \mathrm{bp}$; this PTV Brazilian sequence is: GAAAGACCTGCTCTGGCGCGAGCTAAAGCGCAATTGTCACCAGGTATTGCACCAATGGTGGCGACAGGGTACAGAAGAGCAAGTACTCCTGACTGGGCAATGGGACTGCATTGCATATCCCTAGGCACCTATTGAGATTTCTCTGGGGCCCACCAGC.

\section{DISCUSSION}

To the best of our knowledge, this is the first molecular report of porcine enteric picornaviruses in wild boars from a South American country. The genetic relationship of the PTV, PSV, and EV-G strains from Brazilian wild boars with other sequences, including different serotypes of these viruses, was demonstrated in the phylogenetic tree. The detection of the three porcine enteric picornaviruses was performed for the highly conserved region of the 5'-NTR of the virus genomes and the primer sets used were suitable for specific detection and differentiation of these three porcine enteric picornaviruses. However, a genomic region under higher selection pressure, such as VP1 gene, should be more useful for deeper phylogenetic analyses and classification of the Brazilian wild-boar strains herein.
The overall frequencies of each virus detected herein are similar to a study performed in the Czech Republic, in which EV-G was most commonly detected, followed by PTV and PSV in the 72 fecal samples evaluated from wild boars up to 1 year of age (Prodělalová 2012). Considering single and mixed infections, the results of both of these studies (Prodělalová 2012) are also convergent, with PTV and EV-G double infections detected in higher frequencies, followed by the triple viral infections. In both studies, PSV was detected with the least frequency. However, we are aware that this is a limited study and a higher number of samples should be evaluated for an adequate comparison with results from other studies.

A study performed in Spain reported that PTV was more frequently detected than PSV and, as it was observed in the 
results of the present study, single infections by PSV were not identified (Cano-Gómez et al. 2013). Despite some differences in the PCR techniques, protocols, and ages of the evaluated animals in the two previous reports (Prodělalová 2012, Cano-Gómez et al. 2013) and in this study, the results are based on molecular assays that target the 5'-NTR region of the porcine enteric picornavirus' RNA. The similarities among the results presented herein, in the Czech and Spanish studies may indicate that wild boars are more susceptible to infection by EV-G and PTV. In addition, Boros et al. (2012a) proposed a novel EV-G genotype, provisionally named PEV-15, after characterizing the complete genome sequence of an EV-G strain from a wild boar. This same research group also suggested that there may be PTV strains well-adapted or specific to wild boar host species (Boros et al. 2012b).

The age-dependent prevalence of porcine enteric picornavirus infections is not well defined. Based on results from domestic pigs, animals of all ages are susceptible to enteric picornavirus infections. However, the infection frequency of these viruses varies within the age groups. Boros et al. (2011) evaluated fecal samples of 10-day-old, 4-week-old, and 3-month-old pigs for EV-G and detected positive results only in the younger age group. On the other hand, the investigation of EV-G infection in pigs with ages varying from 4 to 26 weeks detected that 10 - to 15 -week-old animals were more frequently infected with this viral species (Yang et al. 2013).

Another study investigated PTV, PSV, and EV-G in suckling ( $<4$ weeks of age), post-weaning (4-12 weeks of age), slaughter ( 6 months of age), and adult pigs and detected the 3 viruses in all age groups, except for PSV, which was not detected in adult animals (Prodělalová 2012). In contrast, a Brazilian study reported the 3 viruses in post-weaning pigs (4-8 weeks old) but did not detect PSV in suckling piglets (1-3 weeks old) (Donin et al. 2014). Co-infections with 2 or 3 porcine enteric picornaviruses were common in the different age groups (Prodělalová 2012, Cano-Gómez et al. 2013, Donin et al. 2014).

Age-related studies of wild boar enteric picornavirus infections are rare, and the results from this animal species must be compared with domestic pig-based data, which are also limited. The present study detected PTV, PSV, and EV-G more frequently in animals up to 7 months of age relative to adult (2- to 4-year-old) wild boars. Another research group reported high frequencies of positive results for EV-G and PTV infections in 6- and 8-week-old wild boars (Boros et al. 2012a, Boros et al. 2012b). Due to the lack of data, the results from these studies represent supplementary information that should be used in further age distribution investigations of porcine enteric picornavirus infections in wild boars.

Sus scrofa, Pecari tajacu, and Tayassu pecari are phenotypically and behaviorally similar and largely distributed in distinct Latin American regions. For these reasons, peccaries were evaluated as possible alternative host species for porcine enteric picornaviruses. Peccaries tested negative for the viruses and in this study they did not represent infection reservoirs.
It is believed that wild boars were largely introduced into Brazilian territory in the beginning of 1990s through the border with Uruguay, possibly motivated by food demands or due to clandestine import for breeding reasons. In that same decade, wild boars were imported from Europe and Canada, which were also intended for breeding. However, some animals escaped from captivity and, currently, their offspring are still free living. Despite the efforts of the Brazilian government to control the growth of the wild boar population, this animal species is currently present in many states of Brazil, living free or in captivity (Deberdt \& Scherer 2007).

Wild boars were noted to be possible infectious disease sources for livestock and/or humans (Ruiz-Fons et al. 2008, Meng et al. 2009); some of these diseases are included in the World Organization for Animal Health's (OIE) list of notifiable diseases and infections (OIE 2014). Many of the reported wild boar virus infections, such as HEV, PoR$\mathrm{VA}$, and porcine influenza A virus are known to infect other animal species and are considered important zoonotic diseases (Ruiz-Fons et al. 2008, Meng et al. 2009, Okadera et al. 2013, Biondo et al. 2014). Therefore, the potential risks of disease transmission among wild animals and livestock and/or the human population cannot be ignored.

\section{CONCLUSIONS}

The expansion and intensification of livestock production systems requires the constant surveillance of emerging and reemerging infectious diseases.

The introduction of microorganisms associated with wild animals in livestock-based farming systems, the interspecies transmission due to increased contact between domestic and wild animals, and the adaptation (genetic mutation) of pathogens to alternative animal species are factors that highlight the importance of the molecular epidemiological monitoring of enteric microbial and potential pathogens in farm animals.

To the authors' knowledge, this study represents the first molecular screening for PTV, PSV, and EV-G from these wild animal species of Latin America.

The surveillance of infectious diseases in wildlife species may positively impact animal welfare, livestock production, and the environment and public health.

Acknowledgements.- The authors are grateful to Anderson L. Carvalho, Gefferson A. Silva, and Angelica Schmeing for their collaboration. We would like to thank the following Brazilian Institutes for financial support: the National Counsel of Scientific and Technological Development (CNPq), the Brazilian Federal Agency for Support and Evaluation of Graduate Education (CAPES), Financing of Studies and Projects (FINEP), and the Araucaria Foundation (FAP/PR). Alfieri A.A., Alfieri A.F., and Leme R.A. are recipients of CNPq fellowships.

\section{REFERENCES}

Alfieri A.A., Parazzi M.E., Takiuchi E., Médici K.C. \& Alfieri A.F. 2006. Frequency of group A rotavirus in diarrhoeic calves in Brazilian cattle herds, 1998-2002. Trop. Anim. Health Prod. 38:521-526.

Bangari D.S., Pogranichniy R.M., Gillespie T. \& Stevenson G.W. 2010. Genotyping of porcine teschovirus from nervous tissue of pigs with and without polioencephalomyelitis in Indiana. J. Vet. Diagn. Invest. 22:594-597.

Bieber C. \& Ruf T. 2005. Population dynamics in wild boar Sus scrofa: eco- 
logy, elasticity of growth rate and implications for the management of pulsed resource consumers. J. Appl. Ecol. 42:1203-1213.

Biondo N., Schaefer R., Gava D., Cantão M.E., Silveira S., Mores M.A.Z., Ciacci-Zanella J.R. \& Barcellos D.E.S.N. 2014. Genomic analysis of influenza A virus from captive wild boars in Brazil reveals a human-like H1N2 influenza virus. Vet. Microbiol. 168:34-40.

Boom R., Sol C.J., Salimans M.M., Jansen C.L., Wertheim-van Dillen P.M. \& Van der Noordaa J. 1990. Rapid and simple method for purification of nucleic acids. J. Clin. Microbiol. 28:495-503.

Boros A., Nemes C., Pankovics P., Bíró H., Kapusinszky B., Delwart E. \& Reuter G. 2012a. Characterization of a novel porcine enterovirus in wild boars in Hungary. Arch. Virol. 157:981-986.

Boros A., Nemes C., Pankovics P., Kapusinszky B., Delwart E. \& Reuter G. 2012b. Porcine teschovirus in wild boars in Hungary. Arch. Virol. 157:1573-1578.

Boros A., Pankovics P. \& Reuter G. 2011. Characterization of a novel porcine enterovirus in domestic pig in Hungary. Infect. Genet. Evol. 11:1096-1102.

Buitrago D., Cano-Gómez C., Agüero M., Fernandez-Pacheco P., Gómez-Tejedor C. \& Jiménez-Clavero M.A. 2010. A survey of porcine picornaviruses and adenoviruses in fecal samples in Spain. J. Vet. Diagn. Invest. 22:763-766.

Cano-Gómez C., García-Casado M.A., Soriguer R., Palero F. \& Jiménez-Clavero M.A. 2013. Teschoviruses and sapeloviruses in faecal samples from wild boar in Spain. Vet. Microbiol. 165:115-122.

Cano-Gómez C., Palero F., Buitrago M.D., García-Casado M.A., Fernández-Pinero J., Fernández-Pacheco P., Agüero M., Gómez-Tejedor C. \& Jiménez-Clavero M.A. 2011. Analyzing the genetic diversity of teschoviruses in Spanish pig populations using complete VP1 sequences. Infect. Genet. Evol. 11:2144-2150.

Deberdt A.J. \& Scherer S.B. 2007. 0 javali asselvajado: ocorrência e manejo da espécie no Brasil. Braz. J. Nature Conservation 5:31-44.

Deng M.Y., Millien M., Jacques-Simon R., Flanagan J.K., Bracht A.J., Carrillo C., Barrette R.W., Fabian A., Mohamed F., Moran K., Rowland J., Swenson S.L., Jenkins-Moore M., Koster L., Thomsen B.V., Mayr G., Pyburn D., Morales P., Shaw J., Burrage T., White W., McIntosh M.T. \& Metwally S. 2012. Diagnosis of Porcine teschovirus encephalomyelitis in the Republic of Haiti. J. Vet. Diagn. Invest. 24:671-678.

Donin D.G., de Arruda Leme R., Alfieri A., Alberton G. \& Alfieri A. 2014. First report of Porcine teschovirus (PTV), Porcine sapelovirus (PSV) and Enterovirus G (EV-G) in pig herds of Brazil. Trop. Anim. Health Prod. 46:523-528.

ICTV 2013. International Committee on Taxonomy of Viruses <http:// www.ictvonline.org/virusTaxonomy.asp> Accessed on 3 June 2014.

Kaku Y., Murakami Y., Sarai A., Wang Y., Ohashi S. \& Sakamoto K. 2007. Antigenic properties of porcine teschovirus 1 (PTV-1) Talfan strain and molecular strategy for serotyping of PTVs. Arch. Virol. 152:929-940.

Kaku Y., Sarai A. \& Murakami Y. 2001. Genetic reclassification of porcine enteroviruses. J. Gen. Virol. 82: 417-424.

Krumbholz A., Dauber M., Henke A., Birch-Hirschfeld E., Knowles N.J., Stelzner A. \& Zell R. 2002. Sequencing of porcine enterovirus groups II and III reveals unique features of both virus groups. J. Virol. 76:5813-5821.

Krumbholz A., Wurm R., Scheck O., Birch-Hirschfeld E., Egerer R., Henke A., Wutzler P. \& Zell R. 2003. Detection of porcine teschoviruses and enteroviruses by LightCycler real-time PCR. J. Virol. Methods 113:51-63.

La Rosa G., Muscillo M., Di Grazia A., Fontana S., Iaconelli M. \& Tollis M. 2006. Validation of RT-PCR assays for molecular characterization of porcine teschoviruses and enteroviruses. J. Vet. Med. B 53:257-265.

Lan D., Ji W., Yang S., Cui L., Yang Z., Yuan C. \& Hua X. 2011. Isolation and characterization of the first Chinese porcine sapelovirus strain. Arch. Virol. 156:1567-1574.
Lin W., Cui S. \& Zell R. 2012. Phylogeny and evolution of porcine teschovirus 8 isolated from pigs in China with reproductive failure. Arch. Virol. 157:1387-1391.

Meng X.J., Lindsay D.S. \& Sriranganathan N. 2009. Wild boars as sources for infectious diseases in livestock and humans. Phil. Trans. R. Soc. B 364:2697-2707.

Moon H.-J., Song D., Seon B.H., Kim H.-K., Park S.-J., An D.-J., Kim J.-M., Kang B.-K. \& Park B.-K. 2012. Complete genome analysis of porcine enterovirus B isolated in Korea. J. Virol. 86:10250.

OIE 2014. World Organisation for Animal Health. <http://www.oie.int/ wahis_2/public/wahid.php/Reviewreport/Review?page_refer=MapFu llEventReport\&reportid=15389, http://www.oie.int/wahis_2/public/ wahid.php/Reviewreport/Review?page_refer=MapFullEventReport\& reportid=15161> e <http://www.oie.int/wahis_2/public/wahid.php/ Reviewreport/Review?page_refer=MapFullEventReport\&report id=15288 $>$ Accessed on 13 Junho 2014 .

Okadera K., Abe M., Ito N., Morikawa S., Yamasaki A., Masatani T., Nakagawa K., Yamaoka S. \& Sugiyama M. 2013. Evidence of natural transmission of group A rotavirus between domestic pigs and wild boars (Sus scrofa) in Japan. Infect. Genet. Evol. 20:54-60.

Prodělalová J. 2012. The survey of porcine teschoviruses, sapeloviruses and enteroviruses B infecting domestic pigs and wild boars in the Czech Republic between 2005 and 2011. Infect. Genet. Evol. 12:1447-1451.

Ruiz-Fons F., Segalés J. \& Gortázar C. 2008. A review of viral diseases of the European wild boar: effects of population dynamics and reservoir role. Vet. J. 176:158-169.

Salles M.W.S., Scholes S.F.E., Dauber M., Strebelow G., Wojnarowicz C., Hassard L., Acton A.C. \& Bollinger T.K. 2011. Porcine teschovirus polioencephalomyelitis in western Canada. J. Vet. Diagn. Invest. 23: 367-373.

Shan T., Li L., Simmonds P., Wang C., Moeser A. \& Delwart E. 2011. The fecal virome of pigs on a high-density farm. J. Virol. 85:11697-11708.

Sozzi E., Barbieri I., Lavazza A., Lelli D., Moreno A., Canelli E., Bugnetti M. \& Cordioli P. 2010. Molecular characterization and phylogenetic analysis of VP1 of porcine enteric picornaviruses isolates in Italy. Transbound. Emerg. Dis. 57:434-442.

Taber A., Altrichter M., Beck H. \& Gongora J. 2011. Family Tayassuidae (Peccaries), p.308-320. In: Wilson D.E. \& Mittermeier R.A. (Eds), Handbook of the Mammals of the World. Vol.2. Lynx Edicions, Barcelona.

Tamura K., Stecher G., Peterson D., Filipski A. \& Kumar S. 2013. MEGA6: molecular evolutionary genetics analysis version 6.0. Mol. Biol. Evol. 30:2725-2729.

Ventura A., Gonzalez W., Barrette R., Swenson S., Bracht A., Rowland J., Fabian A., Moran K., Mohamed F., O’Hearn E., Jenkins-Moore M., Toms D., Shaw J., Morales P., Pyburn D., Carrillo C., Mayr G., McIntosh M. \& Deng M. 2013. Virus and antibody diagnostics for swine samples of the Dominican Republic collected in regions near the border to Haiti. ISRN Virology 2013:1-7

Yang S., Wang Y., Shen Q., Zhang W. \& Hua X. 2013. Prevalence of porcine enterovirus 9 in pigs in Middle and Eastern China. Virol. J. 10:99.

Zell R., Dauber M., Krumbholz A., Henke A., Birch-Hirschfeld E., Stelzner A., Prager D. \& Wurm R. 2001. Porcine teschoviruses comprise at least eleven distinct serotypes: molecular and evolutionary aspects. J. Virol. 75:1620-1631.

Zell R., Krumbholz A., Henke A., Birch-Hirschfeld E., Stelzner A., Doherty M., Hoey E., Dauber M., Prager D. \& Wurm R. 2000. Detection of porcine enteroviruses by nRT-PCR: differentiation of CPE groups I-III with specific primer sets. J. Virol. Methods 88:205-218.

Zhang W., Yang S., Shen Q., Ren L., Shan T., Wei J., Cui L. \& Hua X. 2012. Complete genome sequence of a novel porcine enterovirus strain in China. J. Virol. 86:7008-7009. 